\title{
Effects of the Aromatherapy Program Using Fir Needle Essential Oil on Stress, Sleep Quality and Fatigue in Middle-Aged Women
}

\author{
Jong-Suk Hong', Woo-Yeol Kim ${ }^{1}$, and Chang-Duck Koo ${ }^{2}$ * \\ ${ }^{1}$ Graduate Department of Forest Therapy, Chungbuk National University, Cheongju 28644, Korea \\ ${ }^{2}$ Department of Forestry, Chungbuk National University, Cheongju 28644, Korea
}

\begin{abstract}
The purpose of this study was to investigate the effect of aromatherapy program using fir needle essential oil on stress, sleep quality, and fatigue of middle aged women. Twenty middle-aged women were divided into experimental group and control group. The experimental group inhaled the fir needle fragrance for 5 minutes and received a back massage with sunflower oil mixed with fir essential oil for 20 minutes. The control group took a rest for 5 minutes instead of inhaling the fragrance of essential oils and received a back massage with only sunflower oil. The experiment was conducted total eight times (twice a week) for four weeks. For the measurement of stress, fatigue, and sleep quality, questionnaires were used to collect data in the pre-test survey and post-test survey. As a result, the scores of physical and psychological stress in the experimental group and the control group were significantly decreased. However, the physical stress was more decreased in the experimental group treated with fir oil aromatherapy. In addition, both groups showed a significant difference in the quality of sleep. Fatigue measurements showed significant changes in both groups, but the fatigue reduction was more significant in the experimental group. These results suggest that massage therapy for the middle-aged women has a positive effect on relieving physical and psychological stress, improving sleep quality and reducing fatigue by assisting metabolism and blood circulation. This study proved that fir needle essential oil can be a good material for aromatherapy to promote health of middle aged women undergoing physical, psychological, and social changes.
\end{abstract}

Keywords: back massage, forest therapy, fragrance inhalation

\section{Introduction}

In human life, middle age is the time when the responsibilities increase at home and in the society. Middle age is the transition period in which people look back on themselves and undergo internal maturity, occasionally showing changes in behavior and consciousness (Sung, 2002). In such middle age, most women experience physical changes such as decrease of immunity from weakened vital functions due to aging, and menopause caused by hormonal changes, while socially they experience psychological problems such as isolation and depression due to changes in family relations and sense of loss. As a result, they face a crisis in life, experiencing psychological frustration from not fulfilling their roles and great stress due to role conflicts and exhausting housework (Choi, 2004; Lee et al., 2008). 
Middle-aged women undergo great stress by experiencing various events in addition to many physical changes (Newman and Newman, 1984; Park and Lee, 2000). Stress is the state in which an individual perceives the environmental stimulation and internal needs imposed by physiological, psychological and social systems, and it refers to the physical and psychological phenomenon experienced when it exceeds the individual's ability to adapt (Park and Lee, 2000). Psychosomatic disorder, which is a physical illness caused by the mental problem of stress, generally affects the human body and causes various diseases such as hypertension, tension headache, hyperventilation syndrome, sleep disorder, neurodermatitis, menstrual pain, depression and anxiety (Go, 2011).

Fatigue is one of the effects that may be caused by all kinds of stress or lack of sleep, and it is an emotion that includes unpleasant, subjective and internal elements that affect the mental aspects. Without sufficient recovery, it reduces concentration, interest and motivation, thereby resulting in overall decrease of physical and mental work capacity in daily life (Trendall, 2000). Fatigue itself cannot be regarded as an illness, but it affects the entire organic body with complicated interaction of physical, mental and other factors (Pickard-Holley, 1991), causing emotional, behavioral and cognitive reactions (Nail and King, 1987).

Sleep is important for health of middle-aged women. Sufficient sleep provides physical and mental stability while insufficient sleep accumulates fatigue in human body, slows down perception, and even causes hallucination (Pilcher et al., 1997). Enough sleep restores physical and mental health as well as security, whereas lack of sleep accumulates fatigue, slows down perception as well as responsive speed or memories in daily life. Therefore, good sleep quality is essential for maintaining and promoting mental and physical health of middle-aged women (Jeong, 2013).

When stress of middle-aged women is not relieved, this leads to identity crisis that adds even more fatigue, reducing the recuperative function through enough sleep. This may also cause financial problems for families and society, which is why research on stress management of middle-aged women is important (Jeong, 2004). As measures to overcome physical, emotional and psychological difficulties of middle-aged women and deal with increased stress, chronic fatigue and sleep difficulty, there is a growing social interest in complementary and alternative therapy such as psychotherapy, kinesiotherapy, massage, relaxation therapy and aromatherapy aside from orthodox medical and drug treatment.

Aromatherapy is the field that is most noticeable among complementary and alternative therapy. Aromatherapy treats various stress symptoms and illnesses such as headache, fatigue and insomnia by inhaling the aroma of essential oil extracted from plants. It is a meaningful attempt using plants to relieve stress of people today, and even promote health and improve the quality of life (Buckle, 1993; Martin et al., 1993; Oh, 1996). In particular, aromatherapy using phytoncide in a forest environment is known to help relax or manage stress in addition to providing comfort and refreshing sensation (Park et al., 2007; Tsunetsugu et al., 2010). However, forest healing for middle-aged women who cannot frequently encounter the forest environment due to busy life, lack of time and inconvenient transportation is difficult to use despite its effectiveness. Thus, inhalation and back massage programs using the aroma of fir essential oil, which has high content of monoterpene among phytoncide, can be an alternative that provides forest healing effects indoors.

Fir (Abies holophylla Maxim) belongs to the pinaceae family and is $40 \mathrm{~m}$ high. The leaves are needle type that are $4 \mathrm{~cm}$ long and have white stomas on the back (Lee, 1982). The accurate name for fir essential oil is fir needle essential oil, generating essential oil with steam distillation from leaves and twigs of various species that belong to the coniferous species. Fir essential oil is colorless or pale yellow, with the strong sweetness of balsam and pleasant fragrance of conifer. It is effective for the nervous system, respiratory system and musculoskeletal system and also relieves anxiety and stress. It is mostly used to relax muscles that became sore due to rheumatism or arthritis and to promote vitality, and brings a secure and comfortable sensation and relaxes tension on the body (Battaglia, 2003).

The objective of this study is to verify whether aromatherapy through aroma inhaling using fir essential oil and aroma 
back massage program using fir essential oil are affective for reducing physical and psychological stress, relieving fatigue and improving sleep quality for middle-aged women, and also to compare the effectiveness with regular massages.

\section{Methods}

\section{Subjects and procedures}

This study is a quasi-experimental research with a pretest-posttest nonequivalent control group design to determine the effects of aromatherapy using fir essential oil and back massage program using oil on middle-aged women's stress, fatigue and sleep quality. A pilot experiment was conducted four times, twice a week for two weeks from December 20, 2017 to January 3, 2018 on four middle-aged women in their 40-50s living in C city. They were proved not to have adverse reaction to the aroma of fir essential oil and discomfort about back massage using fir essential oil.

This experiment implements total 8 sessions of the program (twice a week for 4 weeks) including the pretest survey from January 22 to February 20, 2018 and compares the conditions before and after the program through the posttest survey. Twenty subjects were selected among middle-aged women who have no mental illness, do not take certain drugs, understand the contents of the survey, are capable of communication and willing to participate in this study. They received explanation about the purpose of the study and precautions before the experiment and submitted the consent of participation. Then, 10 subjects in the experimental group and 10 subjects in the control group were randomly selected.

\section{Research design}

This study is an experimental research that examines the effects of aromatherapy programs on middle-aged women's stress, fatigue and sleep quality, and the research design is as shown in Figure 1.

\section{Materials and treatment}

\section{Materials: Fir essential oil and carrier oil}

Fir essential oil used in this experiment is produced by The Aroma in Life through steam distillation using fir needles and twigs from Gangwon-do as raw materials. Visually it is pale yellow and has a refreshing and pleasant fragrance of conifer. Carrier oil is sunflower oil (Korea, JNC Benjarong) that is pale gold and light, extracted from sunflower seeds. It softens the skin touched when massaging, and serves as a solvent that safely transmits aroma oil into the skin (Choi, 2015). Aroma massage oil is made by diluting $10 \mathrm{ml}$ sunflower oil with $2-3 \%$ fir essential oil.

\section{Treatment}

The experiment was conducted at 00 aesthetic salon located in $\mathrm{C}$ city, and the salon was managed at the temperature of $22-24^{\circ} \mathrm{C}$ and humidity of $40-50 \%$ to retain a comfortable and pleasant sensation. The bed maintained a cozy temperature for the subjects to relax, creating a quiet and comfortable atmosphere. The experiment was conducted total 8 times (twice a week) for 4 weeks, with each session taking 30 minutes. The experimental group inhaled the aroma of fir essential oil for the first 5 minutes, received back massage using carrier oil mixed with fir essential oil for 20 minutes, and relaxed for 5 minutes after that. The control group relaxed for the first 5 minutes during which the experimental group inhaled the aroma of fir essential oil, received back massage using general carrier oil without mixing fir essential oil for 20 minutes, and relaxed for 5 more minutes. To come up with accurate results, the experiment was conducted on a fixed day and time every week. 


\section{Subjects: women aged $40 \sim 50(N=20)$}

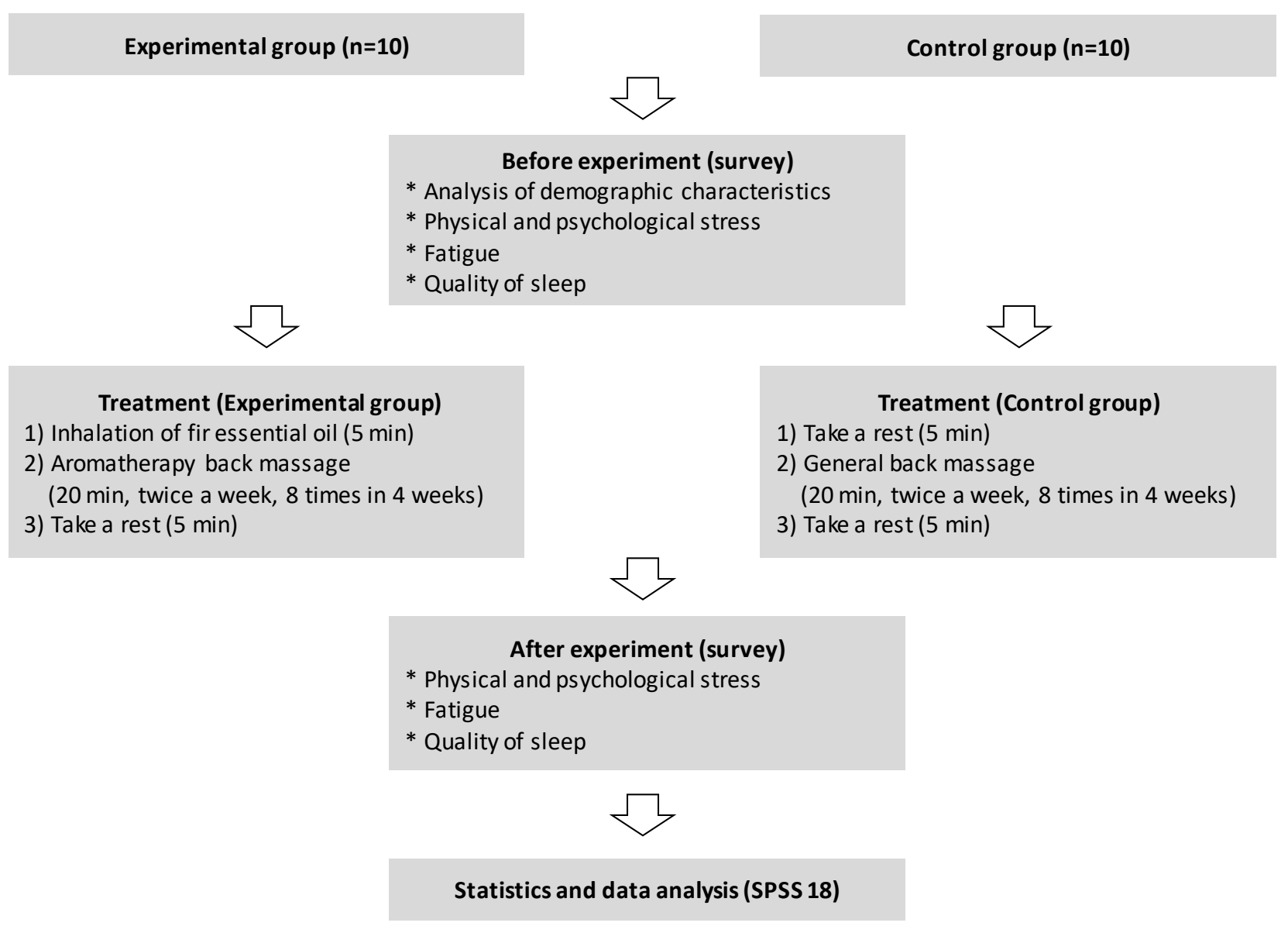

Figure 1. Research design for this study.

\section{- Aroma inhalation}

Aroma was inhaled in dry inhalation method in which pure fir essential oil was directly inhaled through the nose. Adrop of fir essential oil was dropped onto a tissue used by women for makeup, which was then waved in front of the subjects $10 \mathrm{~cm}$ away from the nose to inhale for 5 minutes. Ten subjects in the experimental group inhaled the aroma for 5 minutes each session in this method, while the control group was to just relax for 5 minutes instead of inhaling the aroma.

\section{- Back massage method}

Back massage is Swedish massage proposed by Pher Hens Rick Ling (1776-1839) in Sweden, which stimulates blood vessels and facilitates blood circulation. It also removes wastes inside bodies, relaxes muscles and joints, relaxes the autonomous nervous system, relieves stress, releases tension and helps secure emotional stability (Nam, 2004). Back massage was given for 20 minutes in a relaxing atmosphere. The experimental group received massage after applying $10 \mathrm{ml}$ sunflower oil mixed with 2-3\% fir essential oil on their backs, while the control group received the same massage after applying only the general sunflower oil without mixing fir essential oil. The experiment was conducted for 4 weeks only because using aroma essential oil continuously for more than 4 weeks may rather reduce the effect or reaction (Oh, 2000). 


\section{Measurement tools}

To measure the results of the experiment, the following scales for each field were used in the pretest survey and posttest survey. The items were the same for both pretest and posttest surveys, but the pretest survey also included a section to identify the general characteristics of the participants. The characteristics are as follows.

\section{- Stress}

Stress was measured using the stress measurement scale developed by Park (1999), which consists of total 30 items such as 15 about physical stress and 15 about psychological stress. Each item was rated on a 4-point scale (0 to 3 points), with higher scores indicating higher level of stress. As for reliability of the tool at the point of development, Cronbach's $\alpha$ was .887 for physical stress and Cronbach's $\alpha$ was .881 for psychological stress. In this study, Cronbach's $\alpha$ was .774 for physical stress and Cronbach's $\alpha$ was .897 for psychological stress.

\section{- Sleep quality}

Sleep quality was measured by the sleep quality measurement tool developed by Snyder-Halpern and Verran (1987, as cited in Oh et al., 1998) and revised by Oh et al. (1998), which consists of total 15 items with 1 reversed item. Each item was rated on a 4-point scale ( 0 to 3 points), with higher scores indicating better sleep quality. As for reliability of the tool at the point of development, Cronbach's $\alpha$ was .75. In this study, Cronbach's $\alpha$ was .914

\section{- Fatigue}

Fatigue is measured by the subjective of fatigue test (SOFT) that is a questionnaire standardized by the Industrial Fatigue Research Committee of Japan Society for Occupational Health and translated by Kim and Sung (1998) in Korean. The measured scores indicate subjective perception of fatigue, and there were total 30 items such as 10 about physical symptoms, 10 about mental symptoms, and 10 about sensory and neurological symptoms. Each item was rated on a 4-point scale (0 to 3 points), with higher scores indicating higher fatigue. As for reliability of the tool at the point of development, Cronbach's $\alpha$ was .82, while in this study, Cronbach's $\alpha$ was .902.

\section{Data processing and analysis methods}

Data was collected from December 20, 2017 to February 20, 2018, and the pretest survey was conducted before the aromatherapy program and the posttest survey after 4 weeks of the program. Data collected in this study was statistically analyzed using the statistical program SPSS 18.0. First, a frequency analysis was conducted to examine the demographic characteristics of the subjects. Second, the aromatherapy and fir essential oil back massage group and general back massage group were randomly assigned, and a t-test for each item was conducted to test the homogeneity of the two groups. Here, 'psychological stress' failed to pass the normality test and thus the non-parametric Mann Whitney U test was conducted.

\section{Results and Discussion}

\section{General characteristics of subjects and homogeneity test}

Table 1 shows the normality test result for homogeneity test. A paired sample t-test was conducted for each item to test the significance of pretest-posttest comparison after comparing the experimental group (aroma inhalation and fir essential oil back massage) and control group (general back massage). Here, 'physical stress' and 'sleep quality' failed to pass the 
Table 1. Shapiro-Wilk normality test for homogeneity before program

\begin{tabular}{ccccccccc}
\hline \multirow{2}{*}{ Item } & Group & $\mathrm{n}$ & $\mathrm{M}$ & $\mathrm{SD}$ & $\begin{array}{c}\text { Test } \\
\text { statistic }\end{array}$ & df & $p$ \\
\hline \multirow{2}{*}{ Physical stress } & Experimental & 10 & 1.180 & 0.248 & 0.985 & 10 & .987 \\
\cline { 2 - 8 } & Control & 10 & 1.161 & 0.285 & 0.958 & 10 & .768 \\
\hline \multirow{2}{*}{ Psychological stress } & Experimental & 10 & 1.187 & 0.391 & 0.837 & 10 & .041 \\
\cline { 2 - 8 } & Control & 10 & 1.186 & 0.279 & 0.964 & 10 & .825 \\
\hline \multirow{2}{*}{ Quality of sleep } & Experimental & 10 & 1.859 & 0.382 & 0.956 & 10 & .737 \\
\hline \multirow{2}{*}{ Fatigue } & Control & 10 & 1.846 & 0.261 & 0.855 & 10 & .067 \\
\hline & Experimental & 10 & 1.503 & 0.525 & 0.977 & 10 & .944 \\
\hline
\end{tabular}

Note. Mean values represent the average of all scores on 0-3 rating scale.

Table 2. Shapiro-Wilk normality test for the differences between before and after the program

\begin{tabular}{|c|c|c|c|c|c|c|c|c|c|}
\hline \multirow{3}{*}{ Item } & \multirow{3}{*}{ Group } & \multirow{3}{*}{$\mathrm{n}$} & \multicolumn{4}{|c|}{ Difference } & \multicolumn{3}{|c|}{ Verification of normal assumption } \\
\hline & & & \multicolumn{2}{|c|}{ Before } & \multicolumn{2}{|c|}{ After } & \multirow{2}{*}{$\begin{array}{c}\text { Test } \\
\text { statistic }\end{array}$} & \multirow{2}{*}{$\mathrm{df}$} & \multirow{2}{*}{$p$} \\
\hline & & & M & SD & M & SD & & & \\
\hline \multirow{2}{*}{ Physical stress } & Experimental & 10 & 1.180 & 0.248 & 0.660 & 0.317 & 0.817 & 10 & .023 \\
\hline & Control & 10 & 1.161 & 0.285 & 0.866 & 0.148 & 0.959 & 10 & .771 \\
\hline \multirow{2}{*}{$\begin{array}{c}\text { Psychological } \\
\text { stress }\end{array}$} & Experimental & 10 & 1.187 & 0.391 & 0.559 & 0.353 & 0.931 & 10 & .461 \\
\hline & Control & 10 & 1.186 & 0.279 & 0.948 & 0.224 & 0.919 & 10 & .352 \\
\hline \multirow{2}{*}{ Quality of sleep } & Experimental & 10 & 1.181 & 0.607 & 1.859 & 0.381 & 0.900 & 10 & .221 \\
\hline & Control & 10 & 1.701 & 0.249 & 1.810 & 0.275 & 0.829 & 10 & .033 \\
\hline \multirow{2}{*}{ Fatigue } & Experimental & 10 & 1.503 & 0.525 & 0.633 & 0.320 & 0.865 & 10 & .087 \\
\hline & Control & 10 & 1.487 & 0.407 & 1.276 & 0.232 & 0.851 & 10 & .060 \\
\hline
\end{tabular}

Note. Mean values represent the average of all scores on 0-3 rating scale.

normality test and thus the non-parametric Wilcoxon rank sum test and Mann Whitney U test was conducted. Table 2 shows the result of the normality test to compare the effects before and after the experiment and between the two groups.

Table 3 shows the general characteristics of the subjects. Fourteen subjects were in their 40s (70.0\%) and 6 were in their $50 \mathrm{~s}(30.0 \%)$, and 10 of them were junior college graduates (50.0\%) and 8 were college graduates (40.0\%). Seven of them were self-employed (35.0\%) and 6 were in professional practice (30.0\%). Ten of them had the average income of less than 4 million KRW (50.0\%), and 15 subjects were married (75.0\%). Seven of them had at least one cup of coffee a day (35.0\%), and 9 subjects did not exercise (45.0\%). Nineteen subjects had back massage experience (95.0\%), 9 of which said because their body felt heavy (45.0\%), which implies that they wanted diversion and care for their physical condition. Fifteen subjects said they slept for at least 4 hours a day (75.0\%), and 11 responded that their menstrual state was regular (55.0\%), while 7 of them said they were in menopause (35.0\%). Sixteen subjects said their health status was normal (80.0\%).

At-test was conducted to test the homogeneity of the experimental group and control group selected by this study, and the results are as shown in Table 4. As for psychological stress, the results of the Mann Whitney test are as shown in Table 5.

As presented in Table 4, the experimental group and control group did not show a significant difference in the pretest scores of physical stress, sleep quality, and fatigue. Psychological stress also did not show any significant difference in the pretest 
Table 3. General characteristics of the subjects

\begin{tabular}{|c|c|c|c|}
\hline & & Frequency & Percent $(\%)$ \\
\hline \multirow{2}{*}{ Age } & $40 \mathrm{~s}$ & 14 & 70.0 \\
\hline & $50 \mathrm{~s}$ & 6 & 30.0 \\
\hline \multirow{3}{*}{ Education } & High school graduate & 2 & 10.0 \\
\hline & Professional college graduate & 10 & 50.0 \\
\hline & College graduate & 8 & 40.0 \\
\hline \multirow{4}{*}{ Career } & Housewife & 5 & 25.0 \\
\hline & Self-employment & 7 & 35.0 \\
\hline & Employee & 2 & 10.0 \\
\hline & Profession & 6 & 30.0 \\
\hline \multirow{3}{*}{ Marital status } & Single & 2 & 10.0 \\
\hline & Married & 15 & 75.0 \\
\hline & Divorced & 3 & 15.0 \\
\hline \multirow{3}{*}{ Monthly income } & Less than 3 million won & 3 & 15.0 \\
\hline & 3-4 million won & 10 & 50.0 \\
\hline & Over 4 million won & 7 & 35.0 \\
\hline \multirow{4}{*}{ Daily coffee consumption } & None & 2 & 10.0 \\
\hline & 1 cup & 7 & 35.0 \\
\hline & 2 cups & 5 & 25.0 \\
\hline & 3 cups & 6 & 30.0 \\
\hline \multirow{4}{*}{ Amount of exercise } & None & 9 & 45.0 \\
\hline & Once a week & 1 & 5.0 \\
\hline & Twice a week & 7 & 35.0 \\
\hline & 3 times a week & 3 & 15.0 \\
\hline \multirow{2}{*}{ Back massage experience } & Have & 19 & 95.0 \\
\hline & None & 1 & 5.0 \\
\hline \multirow{5}{*}{ Purpose of back massage } & Diversion & 9 & 45.0 \\
\hline & Pain & 5 & 25.0 \\
\hline & Tired & 3 & 15.0 \\
\hline & Healing & 2 & 10.0 \\
\hline & Others & 1 & 5.0 \\
\hline \multirow{4}{*}{ Hours of sleep } & Less than 4 hours & 1 & 5.0 \\
\hline & 4 to 5 hours & 15 & 75.0 \\
\hline & 6 to 7 hours & 1 & 5.0 \\
\hline & More than 7 hours & 3 & 15.0 \\
\hline \multirow{3}{*}{ Menstruation cycle } & Regular & 11 & 55.0 \\
\hline & Irregular & 2 & 10.0 \\
\hline & Others & 7 & 35.0 \\
\hline \multirow{3}{*}{ Health status } & Bad & 1 & 5.0 \\
\hline & Fair & 16 & 80.0 \\
\hline & Good & 3 & 15.0 \\
\hline
\end{tabular}

scores between the two groups. In all sub-fields measuring the effects of the aromatherapy program, the two groups did not show a significant difference in pretest scores. Thus, the two groups are homogenous groups without much difference.

\section{Effects of the aromatherapy program on middle-aged women's stress, sleep quality, and fatigue}

Table 5 examined the results of the treatment on the experimental group that included aroma inhalation and aroma back 
Table 4. Homogeneity test of stress between experimental and control group $(\mathrm{N}=20)$

\begin{tabular}{|c|c|c|c|c|c|c|c|}
\hline Item & Group & $\mathrm{n}$ & M & SD & $\begin{array}{c}\text { Test } \\
\text { statistic }\end{array}$ & $\mathrm{df}$ & $p$ \\
\hline \multirow{2}{*}{ Physical stress } & Experimental & 10 & 1.180 & 0.248 & \multirow{2}{*}{0.169} & \multirow{2}{*}{9} & \multirow{2}{*}{.870} \\
\hline & Control & 10 & 1.161 & 0.285 & & & \\
\hline \multirow{2}{*}{ Quality of sleep } & Experimental & 10 & 1.859 & 0.382 & \multirow{2}{*}{0.094} & \multirow{2}{*}{9} & \multirow{2}{*}{.927} \\
\hline & Control & 10 & 1.846 & 0.261 & & & \\
\hline \multirow{2}{*}{ Fatigue } & Experimental & 10 & 1.503 & 0.525 & \multirow{2}{*}{0.155} & \multirow{2}{*}{9} & \multirow{2}{*}{.880} \\
\hline & Control & 10 & 1.487 & 0.407 & & & \\
\hline \multirow{2}{*}{ Psychological stress } & Experimental & 10 & 1.187 & 0.391 & \multirow{2}{*}{48} & \multirow{2}{*}{-} & \multirow{2}{*}{$.879^{\mathrm{z}}$} \\
\hline & Control & 10 & 1.179 & 0.210 & & & \\
\hline
\end{tabular}

Note. Mean values represent the average of all scores on 0-3 rating scale.

${ }^{\mathrm{z}}$ At Table 1, psychological stress did not satisfy the normality test and thus $p$-value was obtained through the Mann Whitney U test, while others were obtained through the t-test.

Table 5. Comparison of before and after treatment of the aroma therapy program

\begin{tabular}{|c|c|c|c|c|c|c|c|c|c|}
\hline \multirow{3}{*}{ Item } & \multirow{3}{*}{ Group } & \multirow{3}{*}{$\mathrm{n}$} & \multicolumn{4}{|c|}{ Difference } & \multicolumn{3}{|c|}{ Verification of normal assumption } \\
\hline & & & \multicolumn{2}{|c|}{ Before } & \multicolumn{2}{|c|}{ After } & \multirow{2}{*}{$\begin{array}{c}\text { Test } \\
\text { statistic }\end{array}$} & \multirow{2}{*}{$\mathrm{df}$} & \multirow{2}{*}{$p$} \\
\hline & & & M & SD & M & SD & & & \\
\hline \multirow{2}{*}{$\begin{array}{l}\text { Psychological } \\
\text { stress }\end{array}$} & Experimental & 10 & 1.187 & 0.391 & 0.559 & 0.353 & 5.642 & 9 & $.000^{* *}$ \\
\hline & Control & 10 & 1.186 & 0.279 & 0.948 & 0.224 & 4.315 & 9 & $.002^{* *}$ \\
\hline \multirow{2}{*}{ Fatigue } & Experimental & 10 & 1.503 & 0.525 & 0.633 & 0.320 & 4.172 & 9 & $.002^{* *}$ \\
\hline & Control & 10 & 1.487 & 0.407 & 1.276 & 0.232 & 3.067 & 9 & $.013^{*}$ \\
\hline \multirow{2}{*}{ Physical stress } & Experimental & 10 & 1.180 & 0.248 & 0.660 & 0.317 & -2.807 & - & $.005^{* * \mathrm{z}}$ \\
\hline & Control & 10 & 1.161 & 0.285 & 0.866 & 0.148 & -2.395 & - & $.017^{*}$ \\
\hline \multirow{2}{*}{ Quality of sleep } & Experimental & 10 & 1.181 & 0.607 & 1.859 & 0.381 & -2.810 & - & $.005^{* *}$ \\
\hline & Control & 10 & 1.701 & 0.249 & 1.810 & 0.275 & -2.333 & - & $.020^{*}$ \\
\hline
\end{tabular}

Note. Mean values represent the average of all scores on 0-3 rating scale.

${ }^{z}$ At Table 2, physical stress and quality of sleep did not satisfy the normality test and thus $p$-value was obtained through the Wilcoxon rank sum test, while others were obtained through the t-test.

${ }^{*} p<.05,{ }^{* *} p<.01$.

massage, and the control group that received general back massage without aroma inhalation. According to Table 2, physical stress and sleep quality do not satisfy the normality test and thus non-parametric Wilcoxon rank sum test was conducted.

After treatment, both the experimental group and control group showed a statistically significant difference in stress, sleep quality and fatigue. More detailed results show that for psychological stress, both the experimental group (M=1.187 before, $M=0.559$ after) and control group ( $M=1.186$ before, $M=0.948$ after) showed a significant decrease of the mean. Also for physical stress, both the experimental group ( $\mathrm{M}=1.180$ before, $\mathrm{M}=0.660$ after) and control group (M=1.161 before, $\mathrm{M}=0.866$ after) showed a decrease after treatment. This is the same with fatigue: both the experimental group $(\mathrm{M}=1.503$ before, $\mathrm{M}=0.633$ after) and control group ( $\mathrm{M}=1.487$ before, $\mathrm{M}=1.276$ after) showed a decrease in fatigue after massage. Sleep quality was increased in both the experimental group ( $M=1.181$ before, $M=1.859$ after) and control group 
Table 6. Comparison of mean values between experimental group and control group before and after treatment

\begin{tabular}{|c|c|c|c|c|c|c|c|}
\hline \multirow{3}{*}{ Item } & \multirow{3}{*}{ Group } & \multirow{3}{*}{$\mathrm{n}$} & \multicolumn{5}{|c|}{ Verification } \\
\hline & & & \multicolumn{2}{|c|}{ Difference } & \multirow{2}{*}{ Test statistic } & \multirow{2}{*}{ df } & \multirow{2}{*}{$p$} \\
\hline & & & M & $\mathrm{SD}$ & & & \\
\hline \multirow{2}{*}{$\begin{array}{c}\text { Psychological } \\
\text { stress }\end{array}$} & Experimental & 10 & 0.628 & 0.351 & \multirow{2}{*}{3.143} & \multirow{2}{*}{18} & \multirow{2}{*}{$.008^{* *}$} \\
\hline & Control & 10 & 0.238 & 0.174 & & & \\
\hline \multirow{2}{*}{ Fatigue } & Experimental & 10 & 0.870 & 0.659 & \multirow{2}{*}{3.492} & \multirow{2}{*}{18} & \multirow{2}{*}{$.005^{* *}$} \\
\hline & Control & 10 & 0.211 & 0.217 & & & \\
\hline \multirow{2}{*}{ Physical stress } & Experimental & 10 & 0.520 & 0.390 & \multirow{2}{*}{18} & \multirow{2}{*}{-} & \multirow{2}{*}{$.015^{*_{\mathrm{Z}}}$} \\
\hline & Control & 10 & 0.295 & 0.341 & & & \\
\hline \multirow{2}{*}{ Quality of sleep } & Experimental & 10 & -0.718 & 0.443 & \multirow{2}{*}{4} & \multirow{2}{*}{-} & \multirow{2}{*}{$.000^{* *}$} \\
\hline & Control & 10 & -0.175 & 0.289 & & & \\
\hline
\end{tabular}

${ }^{\mathrm{z}}$ At Table 2, physical stress and quality of sleep did not satisfy the normality test and thus $p$-value was obtained through the Mann Whitney $\mathrm{U}$ test, while others were obtained through the t-test.

${ }^{*} p<.05,{ }^{*}{ }^{*} p<.01$.

( $\mathrm{M}=1.701$ before, $\mathrm{M}=1.810$ after). In conclusion, both the aroma inhalation and aroma oil back massage and general back massage were effective in reducing stress, recovering fatigue and improving sleep quality of middle-aged women more or less.

This result is consistent with the study by Son (2013) claiming that aroma back massage using essential oil such as lavender and ylang-ylang had effect on reduction of middle-aged women's physical and psychological stress. It is also partially consistent with the study by Takeda et al. (2008) showing that massage has physical and psychological effects as well as effects in relieving muscle stress, and vegetable aroma oil in particular is effective in reducing fatigue and giving a pleasant sensation. The experiment on sleep quality showed significant results in both the experimental group and control group, which indicated that sleep quality could be improved only with back massage. This result is partially consistent with the study by Ju et al. (2013) proving that massage in general improves sleep satisfaction.

The control group that received general massage without aromatherapy also showed effect in stress reduction and fatigue recovery. Therefore, Table 5 and Table 6 examined the mean difference between the two groups before and after the treatment to determine whether aromatherapy improves the massage effect for middle-aged women. Among the items, 'physical stress' and 'sleep quality' do not satisfy the normality test in Table 2 and thus non-parametric Mann Whitney test was conducted.

As a result, the experimental group that also received aromatherapy showed a significantly greater massage effect than the control group. In psychological stress, the mean score decrease of the experimental group ( $\mathrm{M}$ before $-\mathrm{M}$ after $=0.628$ ) was greater than the decrease of the control group ( $\mathrm{M}$ before $-\mathrm{M}$ after $=0.238$ ). Also in physical stress, the decrease of the experimental group ( $\mathrm{M}$ before $-\mathrm{M}$ after $=0.520$ ) was greater than the decrease of the control group $(\mathrm{M}$ before $-\mathrm{M}$ after $=0.295)$. As for fatigue, the experimental group $(\mathrm{M}$ before $-\mathrm{M}$ after $=0.870)$ decreased more than the control group $(\mathrm{M}$ before $-\mathrm{M}$ after $=0.211$, while in sleep quality, the experimental group $(\mathrm{M}$ before $-\mathrm{M}$ after $=-0.718)$ showed a greater improvement than the control group ( $\mathrm{M}$ before $-\mathrm{M}$ after $=-0.175$ ). This result is consistent with the study by Lim (2015) in which aroma back massage was applied to middle-aged women and found out that it is more effective in physical and psychological stress, and it is also consistent with the argument by Takeda et al. (2008) that aroma massage therapy is more effective in fatigue recovery compared to general massage therapy. Moreover, it is also in line with the argument by 
Lee (2011) that aroma massage is effective for reducing pain and fatigue.

\section{Conclusion}

This study was conducted to determine whether aroma inhalation in the aromatherapy program using fir essential oil and aroma back massage with fir essential oil among complementary and alternative therapy have positive effects on stress, sleep quality and fatigue of modern middle-aged women exposed to all kinds of stress. To this end, 20 middle-aged women participated in total 8 sessions of the program, twice a week for 4 weeks, from January 22 to February 20, 2018. A pretest survey was conducted and then a posttest survey after the program to compare the status of the subjects before and after implementing the program.

The results showed that both the experimental group participating in the aromatherapy program using fir essential oil and the control group that did not receive aromatherapy showed a significant decrease in the scores of physical and psychological stress.

This is consistent with the argument by Jang (2007) in previous research that back massage is effective in relieving stress. However, in this study, the reduction of physical stress was more significant in the experimental group receiving aromatherapy than the control group. Furthermore, both groups showed a significant difference in sleep quality, indicating that sleep quality improves just by receiving back massage. Fatigue showed significant changes in both groups, but the reduction was more significant in the experimental group that received aromatherapy.

Considering these results, massage therapy to promote middle-aged women's health helps facilitate metabolism and blood circulation, thereby having positive effects on reducing physical and $\bullet$ psychological stress, improving sleep quality, and reducing fatigue. In addition, as provided in the previous studies by Lim (2015) and Takeda et al. (2008) physical stress and fatigue are reduced more significantly when aromatherapy is also included. This is consistent with the study by Son (2013) that fir essential oil massage through aromatherapy promotes lymphatic drainage, relieves fatigue, has a calming effect and gives emotional stability, thereby promoting health and improving the quality of life for middle-aged women.

This study proved that fir essential oil containing phytoncide can be a good material for aromatherapy and that inhalation using fir essential oil and fir essential oil aroma back massage are effective for promoting health of middle-aged women undergoing physical, psychological, mental and social changes. This study is expected to lead to more active research so that essential oil produced in trees with high content of aroma substances in forests can be applied as a means of aromatherapy.

\section{References}

Battaglia, S. 2003. The complete guide to aromatherapy (2nd ed.). Queensland, Australia: Perfect Potion.

Buckle, J. 1993. Aromatherapy. Nurs. Times 89(20):32-35.

Choi, J.Y. 2004. Assessment of dietary in take and physical activity, and development of health-promoting lifestyle model for highly educated married, employed and unemployed women. Doctoral dissertation, Chungnam National University, Daejeon, Korea.

Choi, M.K. 2015. Aromatherapy guide (pp.115). Daejeon, Korea: Benjarong Aromatherapy.

Go, G.B. 2011. Stress \& psychosomatic medicine. Seoul, Korea: Ilchokak Publishing.

Jang, S.S. 2007. Effects of back massage on stress relief. Master's thesis, Kwangju Women's University, Kwangju, Korea. Jeong, M.S. 2013. A study on the relationship between job stress, sleep quality and responses of working nurses. Master's 
thesis, Koshin University, Busan, Korea.

Jeong, M.W. 2004. A study on the effects of aroma inhalation method using sweet orange essential oil on stress in middle-age women. Master's thesis, Chung-Ang University, Seoul, Korea.

Ju, M.S., S. Lee, I. Bae, M.H. Hur, K. Seong, and M.S. Lee. 2013. Effects of aroma massage on home blood pressure, ambulatory blood pressure and sleep quality in middle-aged women with hypertension. Evid. Based Complement. Alternat. Med. 2013:ID403251. DOI: 10.1155/2013/403251

Kim, S.J. and M.S. Sung. 1998. Subjective symptoms in fatigue in hospital nurses. J. Korean Acad. Nurs. 28(4):908-919.

Lee, C.B. 1982. A dictionary of Korean plants. Seoul, Korea: Hyangmun Publishing.

Lee, J.E., M.S. Chae, K.S. Hyun, and P.W. Park. 2008. Effects of neurofeedback and Cranio-Sacral therapy on fatigue and stress resistance in Korean middle aged women. J. Korean Acad. Psychiatr. Ment. Health Nurs. 17(2):129-139.

Lee, M.J. 2011. The effects of aroma massage on myofascial pain syndrome and fatigue: Focus on lavender, rosemary and juniper berry oil. Master's thesis, Kyonggi National University, Suwon, Korea.

Lim, K.M. 2015. The effectiveness of aroma back massage on anxiety and stress in middle-aged women raising grandchildren. Master's thesis, Catholic University, Seoul, Korea.

Martin, S., E. Padilla, M. Ocete, J. Galvez, J. Jiménez, and A. Zarzuelo. 1993. Anti-inflammatory activity of the essential oil of Bupleurum fruticescens. Planta Med. 59(6):533-536.

Nail, L.M. and K.B. King. 1987. Fatigue. Semin. Oncol. Nurs. 3(4):257-262. DOI:10.1016/S0749-2081(87)80016-5

Nam, T.Y. 2004. Natural basic Swedish massage. Changwon, Korea: Design People.

Newman, B.M. and P.R. Newman. 1984. Development through life: A psychosocial approach (3rd ed). Homewood, IL: Dorsey Press.

Oh, H.G. 1996. Natural Medicine of the mystery. Seoul, Korea: Garam Publishing.

Oh, H.G. 2000. Aromatherapy (pp. 13-42). Seoul, Korea: Yangmun Publishing.

Oh, J.J., M.S. Song, and S.M. Kim. 1998. Development and validation of Korean sleep scale A. J. Korean Acad. Nurs. 28(3):563-572.

Park, B.H. and Y.S. Lee. 2000. The relationship between the stress and climacteric symptoms of middle-aged women. J. Korean Acad. Womens Health Nurs. 6(3):383-397.

Park, J.B., Q.S. Auh, Y.H. Chun, J.Y. Lee, and J.P. Hong. 2007. The effect of the phytoncide in decreasing the mouth odor. Korean J. Oral Med. 32(2):151-156.

Park, S.Y. 1999. Stress and my health. Health Promotion Newsletter from Gwangju Metropolitan City. 11(84):7-9.

Pickard-Holley, S. 1991. Fatigue in cancer patients. A descriptive study. Cancer Nurs. 14(1):13-19.

Pilcher, J.J., D.R. Ginter, and B. Sadowsky. 1997. Sleep quality versus sleep quantity: Relationships between sleep and measures of health, well-being and sleepiness in college students. J. Psychosom. Res. 42(6):583-596.

Son, H.O. 2013. Effects of aroma back on the relief of middle-aged women's stress and pain. Master's thesis. Changwon National University, Changwon, Korea.

Sung, M.H. 2002. Self-reported climacteric symptoms, self concept and depression in middle-aged women. J. Korean Acad. Adult Nurs. 14(1):102-113.

Takeda, H., J. Tsujita, M. Kaya, M. Takemura, and Y. Oku. 2008. Differences between the physiologic and psychologic effects of aromatherapy body treatment. J. Altern. Complement. Med. 14(6):655-661. DOI:10.1089/acm.2007.0591

Trendall, J. 2000. Concept analysis: Chronic fatigue. J. Adv. Nurs. 32(5):1126-1131.

Tsunetsugu, Y., B.J. Park, and Y. Miyazaki. 2010. Trends in research related to "Shinrin-yoku" (taking in the forest atmosphere or forest bathing) in Japan. Environ. Health Prev. Med. 15(1):27-37. DOI:10.1007/s12199-009-0091-z 